\title{
Radium-223 chloride: a potential new treatment for castration-resistant prostate cancer patients with metastatic bone disease
}

This article was published in the following Dove Press journal:

Cancer Management and Research

7 January 2013

Number of times this article has been viewed

\section{Michael R Harrison \\ Terence Z Wong \\ Andrew J Armstrong \\ Daniel J George}

Duke Cancer Institute, Durham, NC, USA
Correspondence: Michael R Harrison Division of Medical Oncology, Duke Cancer Institute, DUMC 102002,

47I Seeley Mudd Building, Durham, NC 27710, USA

$\mathrm{Tel}+\mathrm{I} 9196684615$

Fax +19196600178

Email michael.harrison@duke.edu
Background: Radium-223 chloride $\left({ }^{223} \mathrm{Ra}\right.$; Alpharadin) is an alpha-emitting radioisotope that targets areas of osteoblastic metastasis and is excreted by the small intestine. When compared with beta-emitters (eg, strontium-89, samarium-153), ${ }^{223}$ Ra delivers a high quantity of energy per track length with short tissue penetration.

Objective: This review describes the mechanism, radiobiology, and preclinical development of ${ }^{223} \mathrm{Ra}$ and discusses the clinical data currently available regarding its safety and efficacy profile.

Methods: Data from clinical trials including abstracts were collected and reviewed using the PubMed Database, as well as the American Society of Clinical Oncology abstract database.

Conclusion: Current bone-targeted therapies fall into two main categories: antiresorptive agents (eg, zoledronic acid, denosumab), which have been shown to delay skeletal-related events, and radiopharmaceuticals (eg, samarium-153), which may have a role in pain palliation. Historically, neither antiresorptive agents nor radiopharmaceuticals have shown definitive evidence of improved overall survival or other antitumor effects in metastatic castrate-resistant prostate cancer (mCRPC). Radiopharmaceuticals are limited by myelosuppresion, thrombocytopenia, and renal excretion. In a recently reported randomized Phase III trial in men with symptomatic bone-metastatic CRPC who had received or were ineligible for docetaxel chemotherapy, ${ }^{223} \mathrm{Ra}$ treatment resulted in improved overall survival and delayed skeletal-related events. Toxicity consisted of minor gastrointestinal side effects and mild neutropenia and thrombocytopenia that were rarely severe. Pending regulatory approval, ${ }^{223} \mathrm{Ra}$ may represent a unique and distinct option for an important subgroup of patients with mCRPC; future trials should address its use in combination or in sequence with existing and novel agents.

Keywords: Alpharadin, ${ }^{223} \mathrm{Ra}$, radium-223, radionuclide therapy, metastatic castrate-resistant prostate cancer, bone metastases

\section{Introduction}

Prostate cancer is the most common cancer in men and the second-leading cause of cancer death in men, with 241,740 new diagnoses and 28,170 deaths projected in the US in 2012. ${ }^{1}$ Advanced prostate cancer has a penchant to metastasize to bone, possibly due to osteomimicry or altered adhesion molecules. ${ }^{2,3}$ Among patients with metastatic, castrate-resistant prostate cancer (mCRPC) treated with first-line chemotherapy, almost $90 \%$ have radiographic evidence of bone metastasis. ${ }^{4,5}$ Morbidity from complications of osseous metastases, such as pathologic fractures, spinal cord compression, and pain, greatly impairs the quality of life of patients with MCRPC. In addition, pain due to $\mathrm{mCRPC}$ is a strong independent prognostic factor for death, and is included in contemporary nomograms for survival in this disease, ${ }^{6-9}$ thus agents that can reduce pain 
and suffering due to metastatic prostate cancer may improve not only quality of life but also quantity of life.

Mitoxantrone chemotherapy and several radioisotopes, such as samarium-153 $\left({ }^{153} \mathrm{Sm}\right)$ and strontium- $89\left({ }^{89} \mathrm{Sr}\right)$, were the first therapies approved for palliation of bone pain in patients with mCRPC, but without evidence of improvement in overall survival. ${ }^{10,11}$ Since 2004, four systemic therapies have been approved on the basis of improvements in overall survival, with varying effects on bone pain and skeletal complications..$^{4,5,12-14}$ These agents, particularly the taxanes docetaxel (Taxotere ${ }^{\circledR}$; Sanofi-Aventis, Bridgewater NJ), cabazitaxel (Jevtana ${ }^{\circledR}$; Sanofi-Aventis), and the novel androgen biosynthesis inhibitor abiraterone acetate $\left(Z^{2}\right.$ tiga $^{\circledR}$; Janssen Biotech, Inc, Horsham, PA), have direct antitumor effects that may result in pain palliation. Contemporaneously, two osteoclast inhibitors (zoledronic acid [Zometa ${ }^{\circledR}$; Novartis AG, Basel, Switzerland] and denosumab [Xgeva ${ }^{\circledR}$; Amgen Inc, Thousand Oaks, CA]) have been approved on the basis of delay of skeletal-related events (SREs; pathologic fracture, spine cord compression, and requirement for radiation or surgery to bone), but without improvements in overall survival (OS). ${ }^{15,16}$ In addition, the novel androgen signaling inhibitor MDV3100 (enzalutamide, Xtandi ${ }^{\circledR}$; Medivation, Inc, San Francisco, CA) has demonstrated improvements in OS and palliative end points; its approval was granted August 31, 2012, as this article went to press. ${ }^{17-19}$ Prior to the development of ${ }^{223} \mathrm{Ra}$ (Alpharadin ${ }^{\circledR}$; Algeta ASA, Oslo, Norway/Bayer AG, Leverkusen, Germany), no specifically bone-targeted therapy has been shown to improve median OS in the population of patients with $\mathrm{MCRPC}$ with osseous metastases.

Survival-prolonging systemic therapies currently approved for mCRPC include docetaxel, cabazitaxel, sipuleucel-T
(Provenge ${ }^{\circledR}$; Dendreon, Seattle, WA), abiraterone, and MDV3100 (Table 1). However, the effects of these therapies on skeletal complications are not well reported. Pain response is the only SRE that has been routinely reported (Table 2), with much fewer data on prevention or delay of SREs. A special case to this has been sipuleucel-T, which is specifically indicated for men with MCRPC who have minimal to no symptoms. As a reference, the palliative chemotherapy regimen of mitoxantrone/prednisone demonstrated a $29 \%$ response on the Present Pain Intensity (PPI) scale versus 12\% with prednisone alone $(P=0.01)$, with a duration of 43 versus 18 weeks $(P<0.0001) .{ }^{10}$ The landmark TAX-327 study showed a pain response of $35 \%$ versus $22 \%(P=0.01)$ on the PPI scale for docetaxel/prednisone versus mitoxantrone/ prednisone, with a duration of 3.5 versus 4.8 months ( $P$ not significant). ${ }^{5}$ Patients who experienced a pain response in this trial were found to have improved overall survival as compared with those men without such a response. ${ }^{7}$ In the post-docetaxel mCRPC setting, cabazitaxel/prednisone showed no improvement over mitoxantrone/prednisone on the PPI scale ( $9.2 \%$ vs $7.7 \% ; P=0.63$; duration not reached) in the TROPIC trial. ${ }^{13}$ In a similar post-docetaxel setting, the COU-AA-301 study demonstrated a $44 \%$ versus $27 \%$ pain response on the Brief Pain Inventory (BPI) scale for abiraterone/prednisone vs placebo/prednisone, with a time to progression of approximately 8 versus 5 months (25th percentile; $P=0.0056) .{ }^{20}$ The great variability in pain response for the control arms (7.7\% for mitoxantrone/prednisone in the TROPIC study, and $27 \%$ for prednisone alone in the COU-AA-301 study) suggests great variability in the reporting methods. Notably, in the COU-AA-301 study, the time to SRE was also delayed to approximately 10 versus 5 months $(P=0.0006)$. There were previously no other data

Table I Overall survival benefit in recent Phase III trials in mCRPC

\begin{tabular}{|c|c|c|c|c|c|}
\hline $\begin{array}{l}\text { Agent } \\
\text { (trial, year) }\end{array}$ & Disease state & Comparator & $\begin{array}{l}\text { Hazard } \\
\text { ratio }\end{array}$ & $\begin{array}{l}\text { Median OS, months } \\
\text { ( } P \text {-value) }\end{array}$ & $\begin{array}{l}\text { FDA } \\
\text { approval }\end{array}$ \\
\hline $\begin{array}{l}\text { Sipuleucel-T } \\
(\text { IMPACT, 20I0) }\end{array}$ & $\begin{array}{l}\text { Chemonaive mCRPC; asymptomatic } \\
\text { or minimally symptomatic }\end{array}$ & Placebo & 0.775 & 25.8 vs $21.7(0.032)$ & Yes \\
\hline $\begin{array}{l}\text { Docetaxel + prednisone } \\
(\text { TAX-327, 2004) }\end{array}$ & Chemonaive mCRPC & $\begin{array}{l}\text { Mitoxantrone }+ \\
\text { prednisone }\end{array}$ & 0.76 & I8.9 vs I $6.5(0.009)$ & Yes \\
\hline $\begin{array}{l}\text { Cabazitaxel + prednisone } \\
(\text { TROPIC, 20I0) }\end{array}$ & Post-docetaxel mCRPC & $\begin{array}{l}\text { Mitoxantrone + } \\
\text { prednisone }\end{array}$ & 0.70 & I5.I vs I2.7 $(<0.000 \mid)$ & Yes \\
\hline $\begin{array}{l}\text { Abiraterone + prednisone } \\
(\text { COU-AA-30I, 2010) })^{14}\end{array}$ & Post-docetaxel mCRPC & Placebo + prednisone & 0.65 & 14.8 vs $10.9(<0.001)$ & Yes \\
\hline $\begin{array}{l}\text { MDV3I00 } \\
\left(\text { AFFIRM, 20I2) }{ }^{17}\right.\end{array}$ & Post-docetaxel mCRPC & Placebo & 0.631 & I8.4 vs I3.6 (0.000I) & Yes \\
\hline $\begin{array}{l}\text { Radium-223 } \\
(\text { ALSYMPCA, 2012) }\end{array}$ & $\begin{array}{l}\text { Bone-metastatic mCRPC; } \\
\text { symptomatic }\end{array}$ & Placebo + BSC & 0.695 & I4.0 vs II. $2(0.00 \mid 85)$ & Pending \\
\hline
\end{tabular}

Abbreviations: mCRPC, metastatic castrate-resistant prostate cancer; OS, overall survival; BSC, best standard of care. 
Table 2 Pain responses in randomized studies of survival prolonging therapies in $\mathrm{MCRPC}$

\begin{tabular}{|c|c|c|c|c|}
\hline Agent & $\begin{array}{l}n \\
\text { (\% with pain) }\end{array}$ & $\begin{array}{l}\text { Pain } \\
\text { scale* }\end{array}$ & $\begin{array}{l}\text { Pain response } \\
\text { ( } P \text {-value) }\end{array}$ & $\begin{array}{l}\text { Duration } \\
\text { (months) }\end{array}$ \\
\hline $\begin{array}{l}\text { Docetaxel + } \\
\text { prednisone }^{5}\end{array}$ & $\begin{array}{l}1006 \\
(45 \%)\end{array}$ & PPI & $\begin{array}{l}35 \% \text { vs } 22 \% \\
(0.01)\end{array}$ & $\begin{array}{l}3.5 \text { vs } 4.8 \\
\text { (NS) }\end{array}$ \\
\hline $\begin{array}{l}\text { Cabazitaxel + } \\
\text { prednisone }^{13}\end{array}$ & $\begin{array}{l}755 \\
(45 \%)\end{array}$ & PPI & $\begin{array}{l}9.2 \% \text { vs } 7.7 \% \\
(0.63)\end{array}$ & NR \\
\hline $\begin{array}{l}\text { Abiraterone + } \\
\text { prednisone }^{14,20}\end{array}$ & $\begin{array}{l}1195 \\
(44 \%)\end{array}$ & BPI & $\begin{array}{l}44 \% \text { vs } 27 \% \\
(0.0002)\end{array}$ & $\begin{array}{l}8 \text { vs } 5 \\
(P=0.0056)^{t}\end{array}$ \\
\hline
\end{tabular}

Notes: ${ }^{2} 25$ th percentile. $*$ Of note, many of these trials used differing pain scales and variable incorporation of composite analgesic scores; thus, cross-trial comparisons are not possible.

Abbreviations: $\mathrm{mCRPC}$, metastatic castrate-resistant prostate cancer; PPI, Present Pain Intensity; NS, not significant; NR, not reached; BPI, Brief Pain Inventory.

regarding prevention or delay of SREs with the other survivalprolonging systemic therapies.

Bone-targeted osteoclast inhibitors and bone-seeking radiopharmaceuticals have been approved for $\mathrm{MCRPC}$ on the basis of prevention or delay of SREs and palliation of pain, respectively. Zoledronic acid, a bisphosphonate that inhibits osteoclasts, significantly delayed the time to SRE versus placebo (approximately 16 versus 11 months, $P=0.009$ ) and also improved pain and analgesia scores. ${ }^{15,21}$ More recently, a monoclonal antibody to the receptor activator of NF- $\mathrm{\kappa B}$ ligand (RANKL), denosumab, has also been approved. In a placebo-controlled Phase III trial, denosumab showed a 3.6-month improvement in time to first SRE over zoledronic acid (20.7 versus 17.1 months; $P=0.0002$ [noninferiority], $P=0.008$ [superiority]). ${ }^{16}$ Of note, neither zoledronic acid nor denosumab demonstrated improvements in prostate-specific antigen (PSA) levels, overall disease progression, or overall survival. Thus, while these are bone-targeted agents, they may have a greater effect on bone health and quality than on the tumor microenvironment, which supports metastatic cancer and promotes treatment resistance. An ideal tumor microenvironment-targeting agent would thus not only prevent symptomatic deterioration but also improve upon disease-related outcomes, particularly OS.

In addition to osteoclast inhibitors, therapeutic radioisotopes that have a predilection to accumulate in bone turnover sites can be administered. These radiopharmaceuticals emit either alpha or beta particles. An alpha particle, which is ejected from a heavy nucleus during alpha decay, consists of two neutrons and two protons (ie, a helium nucleus). ${ }^{22} \mathrm{~A}$ beta particle is an electron released from a nucleus containing excess neutrons during beta decay, in which one neutron is converted to a proton, an electron, and a neutrino. ${ }^{22}$ Both $\alpha$ - and $\beta$-particles can deliver damaging radiation locally to cancerous cells. The most commonly used radiopharmaceuticals, both $\beta$-emitters, currently approved in the US for treatment of bone metastases are ${ }^{89} \mathrm{Sr}\left(\right.$ Metastron $^{\circledR}$; GE Healthcare, Arlington Heights, IL) and ${ }^{153} \mathrm{Sm}$ (Quadramet ${ }^{\mathbb{B}}$; EUSA Pharma, Oxford, UK). There are key differences in the physical properties of these radioisotopes, which have important clinical implications (Table 3). ${ }^{89} \mathrm{Sr}$ is a pure $\beta$-emitter with a long half-life (50 days), whereas ${ }^{153} \mathrm{Sm}$ has a much shorter half-life (1.9 days) and is also a $\gamma$-emitter, which allows posttreatment scintigraphic imaging. In addition, ${ }^{89} \mathrm{Sr}$ emits higher-energy beta particles, resulting in greater tissue penetration and consequently higher bone marrow toxicity. Multiple randomized trials have been conducted with ${ }^{89} \mathrm{Sr}$ and ${ }^{153} \mathrm{Sm}$ in patients with mCRPC. ${ }^{23-29}$ There was no demonstration of improvement in overall survival in Phase III trials, although palliative benefits were seen that formed the basis of US FDA approval. One recent meta-analysis concluded that, although there is some evidence that these beta-emitting radioisotopes might provide a small benefit with complete reduction in pain over 1-6 months and no increase in analgesic use, severe adverse effects (mainly leukopenia and thrombocytopenia) are relatively frequent. ${ }^{11}$ Nonetheless, ${ }^{153} \mathrm{Sm}$ can be administered in repeat doses, once hematologic toxicities have recovered, for persistent pain. ${ }^{30}$ Other limitations to ${ }^{89} \mathrm{Sr}$ and ${ }^{153} \mathrm{Sm}$ include the fact that they are renally excreted; this is not ideal in patients with genitourinary cancers. Overall, ${ }^{89} \mathrm{Sr}$ and ${ }^{153} \mathrm{Sm}$ might provide some palliative of pain, at the potential expense of significant hematologic toxicities and without demonstrated OS benefit. Ongoing work of these agents in combination with chemotherapy may optimize their efficacy. ${ }^{31-34}$

In comparison to beta-emitting radioisotopes, radium$223\left({ }^{223} \mathrm{Ra}\right.$; Alpharadin ${ }^{\circledR}$, Algeta) is an $\alpha$-emitter that delivers

Table 3 Properties of selected radiopharmaceuticals for treatment of bone metastases in mCRPC

\begin{tabular}{|c|c|c|c|c|c|c|}
\hline Radionuclide & Particle & $\begin{array}{l}\text { Primary } \\
\text { excretion }\end{array}$ & $\begin{array}{l}\text { Physical } \\
\text { half-life (days) }\end{array}$ & Particle energy in MeV & $\begin{array}{l}\text { Tissue range } \\
(\mathrm{mm})\end{array}$ & $\begin{array}{l}\text { Bone surface to red } \\
\text { bone marrow dose ratio }\end{array}$ \\
\hline Radium-223 (Alpharadin $\left.{ }^{\circledR}\right)^{38}$ & Alpha & Small bowel & 11.4 & 5.56 & $<0.1$ & 10.3 \\
\hline Samarium-I53 (Quadramet $\left.{ }^{\circledR}\right)^{76^{*}}$ & Beta & Kidney & 1.9 & 0.81 & 3 & $4.4^{\dagger}$ \\
\hline Strontium-89 (Metastron $\left.{ }^{\circledR}\right)^{77^{*}}$ & Beta & Kidney & 50.5 & 1.46 & 8 & $1.6^{\dagger}$ \\
\hline
\end{tabular}

Notes: "Values in these rows taken from prescribing information ${ }^{75,76}$ insert unless otherwise noted. ${ }^{\dagger}$ Calculated based on values in product's prescribing information. Abbreviations: $\mathrm{mCRPC}$, metastatic castrate-resistant prostate cancer; $\mathrm{MeV}$, mega-electronvolts. 
radiation with a higher biologic effect to a more localized area. In a large randomized Phase III trial, ${ }^{223} \mathrm{Ra}$ has recently demonstrated improvements in OS, time to first SRE, and biochemical parameters, with a remarkably tolerable adverseevent profile, in men with bone-metastatic CRPC. ${ }^{35}$ While ${ }^{223} \mathrm{Ra}$ has not yet been approved for use in the US, and there is little experience in the US with the use of this agent, it represents the first bone-targeted therapeutic radiopharmaceutical to demonstrate a survival benefit, which has been the benchmark for recent FDA approvals in this disease setting. An expanded access trial of ${ }^{223} \mathrm{Ra}$ in men with $\mathrm{mCRPC}$ with bone metastases is planned. ${ }^{36}$ Many questions have arisen as to the appropriate sequencing of existing and novel therapies with ${ }^{223} \mathrm{Ra}$ and if/how to combine ${ }^{223} \mathrm{Ra}$ with these systemic therapies. This manuscript will review the preclinical and clinical development of ${ }^{223} \mathrm{Ra}$, and comment on its potential role and use in the armamentarium of therapy for mCRPC.

\section{Radiobiology, mechanism of action, and preclinical development of ${ }^{223} \mathbf{R a}$}

Bone-seeking therapeutic radiopharmaceuticals are unique among anticancer therapies in that they actually target the stroma rather than the tumor itself: the target is calcium hydroxyapatite in bone. Ionizing radiation can thus be selectively delivered to areas of increased osteoblastic activity, allowing the targeting of multiple metastases simultaneously, including both symptomatic as well as asymptomatic lesions. As mentioned above, the commonly used clinically available radiopharmaceuticals are $\beta$-emitters, with ${ }^{89} \mathrm{Sr}$ and ${ }^{153} \mathrm{Sm}$ the most well studied. ${ }^{37}$ Following injection of ${ }^{89} \mathrm{Sr}$, radiation doses are delivered to the osseous target lesions at low dose rates. ${ }^{38}$ Between 16 weeks and 1 year, absorbed doses in the 20-40 Gy range are deposited as a steadily declining dose rate. ${ }^{39,40}$ Because of its higher dose rate and the shorter range (ie, tissue penetration), ${ }^{153} \mathrm{Sm}$ may have an improved therapeutic index compared with that of ${ }^{89} \mathrm{Sr}$ (Table 3). ${ }^{38}$ Due to its relatively shorter half-life, repeated administration of ${ }^{153} \mathrm{Sm}$ is feasible for persistent or recurrent bone pain provided adequate hematologic function returns; however, effects on bone marrow remain a limitation. ${ }^{30}$ This suggests that an agent with less depth of tissue penetration but similar or higher biologic effect is needed to facilitate repeated dosing. One potential reason for difficulty demonstrating antitumor and survival benefits with $\beta$-emitters could be related to this dosing limitation.

Cationic radium is a calcium mimetic (located in the same column of the periodic table as calcium), and as such naturally targets areas of bone turnover without the need for a carrier. (Recall that the bone stores $99 \%$ of the human body's calcium and $85 \%$ of the phosphorous. Blood levels of calcium and bone resorption/formation are both tightly regulated by various hormones. ${ }^{41}$ ) For example, Radium-224 $\left({ }^{224} \mathrm{Ra}\right)$ has been used extensively for treatment of ankylosing spondylitis, a chronic inflammatory disease of the axial skeleton characterized by new bone formation. ${ }^{42}{ }^{223} \mathrm{Ra}$ has a half-life of 11.4 days, produces four alpha particles from decay through short-lived daughter radionuclides, and has advantages over ${ }^{224} \mathrm{Ra}$ in terms of the decay chain. ${ }^{43223} \mathrm{Ra}$ was selected for biomedical applications based on its favorable decay chain and half-life. ${ }^{43}$ In contrast to $\beta$-emitters, which have a low linear energy transfer (LET) and track lengths of up to several millimeters, $\alpha$-emitters deliver a much more densely ionizing (high LET) radiation with an immense quantity of energy per track length and much shorter tissue penetration $(<100 \mu \mathrm{m}$, or $2-10$ cell diameters). The key physical differences in selected $\alpha$ - and $\beta$-emitters are summarized in Table 3, and the mechanism of action of ${ }^{223} \mathrm{Ra}$ is summarized in Figure 1. Because alpha-particle irradiation induces mostly double-stranded DNA breaks, cellular repair mechanisms may be less effective. ${ }^{44}$ Lesions with clones of tumor cells remaining dormant in $\mathrm{G}_{0}$ of the cell cycle may be eradicated by high LET radiation from $\alpha$-emitters. ${ }^{38,45}$ In addition, the limited penetration depth also results in lower radiation dose to the marrow and other adjacent normal tissues.

Radiation safety precautions associated with ${ }^{223} \mathrm{Ra}$ therapy are minimal. Following therapy with ${ }^{223} \mathrm{Ra}$, the risk of radiation exposure to others is very small, with the main recommendation being to maintain good hygiene. While ${ }^{153} \mathrm{Sm}$ and ${ }^{89} \mathrm{Sr}$ are excreted primarily by the kidneys, the major route of excretion of ${ }^{223} \mathrm{Ra}$ is through the feces, with only a small fraction of renal excretion; this reduces the chances of contamination. The patient's external radiation exposure to others is low enough to allow patients to be

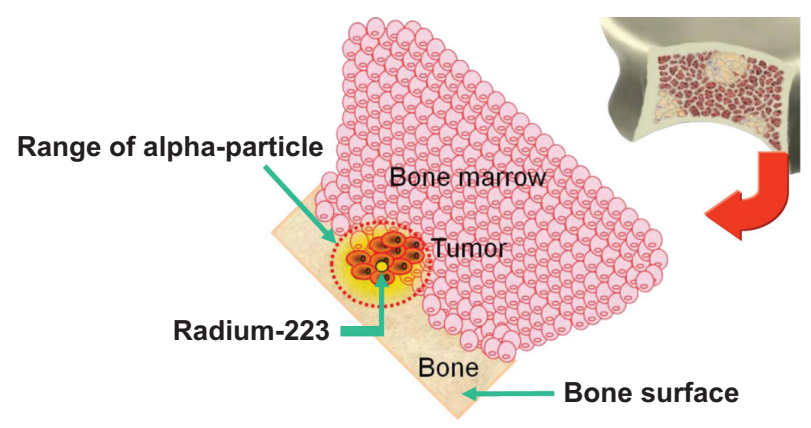

Figure I Mechanism of action for the targeting of osseous metastases by ${ }^{223} \mathrm{Ra}$. Reprinted with permission from Algeta ASA, from 2012 ASCO GU Symposium presentation.

Abbreviation: ${ }^{223} \mathrm{Ra}$, radium-223. 
immediately released under 10 CFR 35.75 following ${ }^{223} \mathrm{Ra}$ administration.

Preclinical studies of ${ }^{223} \mathrm{Ra}$ demonstrated its potential to be bone marrow-sparing, with promising antitumor activity and favorable biodistribution. In mice, bone uptake of ${ }^{223} \mathrm{Ra}$ compared with ${ }^{89} \mathrm{Sr}$ was similar; however, estimates of dose to marrow cavities showed that ${ }^{223} \mathrm{Ra}$ could be less toxic to bone marrow than $\beta$-emitters. ${ }^{46}$ In a nude rat model of osseous metastases resistant to chemotherapy and biphosphonates, rats treated with ${ }^{223} \mathrm{Ra}$ had superior symptom-free survival. ${ }^{47}$ A biodistribution study in a dog with bone cancer injected with ${ }^{223} \mathrm{Ra}$ showed elimination via intestinal clearance, with low activity in the intestinal wall that was similar to other soft tissues. ${ }^{38}$ In addition, examination of these canine specimens using $\alpha$-track microautoradiography demonstrated some concentration of the $\alpha$-emitter on the surfaces of trabecular bone and a very high accumulation in the osteoblastic bone matrix.

\section{Clinical evaluation of ${ }^{223} \mathbf{R a}$ Phase I studies}

Based on the promising preclinical results, a Phase I doseescalation and safety study was conducted in 25 men and women with prostate $(n=15)$ and breast $(n=10)$ cancers (AT1-BC-1) ${ }^{43}$ Five patients were treated with a single dose of ${ }^{223} \mathrm{Ra}$ at each of the following dose levels and followed for 8 weeks: $46,93,163,213$, or $250 \mathrm{kBq} / \mathrm{kg}$. Subjects were followed for 8 weeks. The patients were observed for dose-limiting toxicity (defined as platelets $<20 \times 10^{9} / \mathrm{L}$ or neutrophils $<0.5 \times 10^{9} / \mathrm{L}$ ) and adverse events (AEs). In addition, the blood-clearance profile of ${ }^{223} \mathrm{Ra}$ was evaluated at 10 minutes and at 1, 4, 24, and 48 hours and 7 days postinjection. Gamma camera scintigraphy was performed in six patients, using the $271 \mathrm{keV}$ peak of the ${ }^{219} \mathrm{Rn}$ daughter to indicate the position of its mother nuclide; this required long acquisition times due to the low number of events. Pain was assessed using the European Organization for Research and Treatment of Cancer QLQ-C 30 questionnaire at baseline, 1,4 , and 8 weeks.

Overall, ${ }^{223} \mathrm{Ra}$ was well-tolerated, and no dose-limiting hematologic toxicity was observed. ${ }^{43}$ Reversible myelosuppression was observed, with nadir counts occurring $2-4$ weeks after administration of ${ }^{223} \mathrm{Ra}$. There was a trend towards increased myelosuppression at higher dose levels. Interestingly, there was more neutropenia than thrombocytopenia (in contrast to $\beta$-emitters, with which thrombocytopenia is often more frequent). There was no anemia above grade 2 or thrombocytopenia above grade 1 observed. Grade 3 leukopenia and neutropenia were only seen at the $\geq 163 \mathrm{kBq} / \mathrm{kg}$ doses in the same two patients, in addition to one isolated instance of leukopenia. The most common AEs were: transient diarrhea (40\% of subjects); bone pain, including "flare" (36\%); fatigue (25\%); nausea (25\%); and vomiting (25\%). Whereas transient diarrhea was observed at all dose levels, nausea and vomiting occurred at the higher dose levels. AEs were generally mild, reversible, and manageable with supportive care (ie, antidiarrheal medication).

Blood radioactivity levels decreased from $12 \%$ of the initial at 10 minutes postinjection to $6 \%$ at 1 hour and $<1 \%$ after 24 hours. By gamma scintigraphy, ${ }^{223} \mathrm{Ra}$ appeared to accumulate in osteoblastic metastases, correlating well with conventional diagnostic ${ }^{99 \mathrm{~m}}$ Tc-MDP bone scans. Serum alkaline phosphatase decreased in both groups of patients, but was greatest in the patients with prostate cancer $(-52.1 \pm 14.8$, mean \pm standard deviation $)$ and significantly different between the groups $(P=0.0028)$. The 16 patients with an elevated serum alkaline phosphatase at baseline (of which eleven had prostate cancer) had a particularly robust decline, which was significantly different than patients with normal-range alkaline phosphatase at baseline. Pain palliation was noted in more than half of the patients, with $52 \%$ reporting improvement at 1 week, $60 \%$ at 4 weeks, and $56 \%$ at 8 weeks. Of note, a "flare" response (transient increase in bone pain) was observed in about one-fifth of patients (seven of 25) during the first week of treatment. This was the first clinical trial of an $\alpha$-emitter for treatment of cancer patients with osseous metastases.

Because of a very tolerable toxicity profile (including mild myelosuppression and gastrointestinal side effects), pharmacodynamic effects consistent with the hypothesized mechanism of action (decline in serum alkaline phosphatase and correlation of gamma scintigraphy with bone scans), and evidence of clinical benefit (improved pain scores compared with baseline in up to $60 \%$ ), ${ }^{223} \mathrm{Ra}$ was deemed to be promising for further study. Also of note, survival in this Phase I study was observed to be greater than 20 months (with $>20$ months' follow-up), which compared favorably to a contemporary Scandinavian randomized trial with ${ }^{89} \mathrm{Sr}$ in a similar population. ${ }^{48} \mathrm{An}$ additional Phase Ib study (BC1-05) of six patients with advanced prostate cancer demonstrated the feasibility of repeat dosing of ${ }^{223} \mathrm{Ra}$, but has only been reported in abstract form. ${ }^{38,49}$ Finally, a separate Phase Ib study (BC1-08) in men with progressive CRPC and two or more bone metastases on bone scan $(n=10)$ did not reach the maximum tolerated dose with escalation up to $200 \mathrm{kBq} / \mathrm{kg}$ and demonstrated targeting of osseous lesions, 
rapid blood clearance, and excretion through the small intestine followed by transit through the large intestine..$^{50}$

\section{Phase II studies}

Two randomized, multicenter Phase II studies in patients with $\mathrm{mCRPC}$ have been published. In the first double-blind, placebo-controlled study (BC1-02), patients were randomized to be given either four intravenous injections of ${ }^{223} \mathrm{Ra}$ at $50 \mathrm{kBq} / \mathrm{kg}$ or placebo every 4 weeks. $^{51}$ In the second double-blind, dose-response study (BC1-04), patients were randomized to a single intravenous injection of ${ }^{223} \mathrm{Ra}$ at 5 , 25,50 , or $100 \mathrm{kBq} / \mathrm{kg} .{ }^{52}$

The first study (BC1-02) aimed to evaluate the effects of repeated ${ }^{223} \mathrm{Ra}$ dosing in men with symptomatic CRPC. ${ }^{51}$ Patients were required to have multiple osseous metastatic lesions or one painful lesion with two consecutive rising PSA values. In addition, all patients had bone pain requiring external-beam radiotherapy (EBRT) and either had bilateral orchiectomy or else were maintained on a luteinizing hormone-releasing hormone agonist during the study. Patients were randomized to receive either four consecutive monthly injections of ${ }^{223} \mathrm{Ra}$ at $50 \mathrm{kBq} / \mathrm{kg}$ or saline. EBRT was given to the most painful bony lesion starting no later than 7 days after the first injection. The primary end points were the mean change in bone alkaline phosphatase (ALP) from baseline to 4 weeks after the last injection and time to occurrence of SREs. Secondary end points included evaluation of safety, serum markers of bone turnover, PSA, and overall survival.

Sixty-four patients were enrolled from eleven centers in Sweden, Norway, and the UK: 33 patients were randomized to EBRT with ${ }^{223} \mathrm{Ra}$ and 31 patients to EBRT with placebo. ${ }^{51}$ No difference in EBRT dose fractionation at baseline was observed between the groups. Hematological toxicity was minimal, with no thrombocytopenia observed in the ${ }^{223} \mathrm{Ra}$ arm compared with one event in a placebo-arm patient. Grade $\geq 2$ neutropenia occurred in three patients treated with ${ }^{223} \mathrm{Ra}$ compared with none treated with placebo. No patient discontinued ${ }^{223} \mathrm{Ra}$ because of treatment-emergent AEs, and there were more serious AEs in the placebo arm. The only statistically significant difference in AEs between the arms was constipation in twelve patients treated with ${ }^{223} \mathrm{Ra}$ (mildmoderate in all but one case) versus two with placebo.

In addition to a tolerable safety profile, evidence of biologic effects and efficacy were demonstrated. ${ }^{51}$ The median change in bone ALP from baseline to 4 weeks after the last study injection was $-65.6 \%$ in the ${ }^{223}$ Ra group compared with $9.3 \%$ in the placebo group $(P<0.0001)$. Median time to first
SRE was 14 weeks in the ${ }^{223} \mathrm{Ra}$ arm versus 11 weeks in the placebo arm $(P=0.257)$, with a hazard ratio (HR) of 1.75 (95\% confidence interval $[\mathrm{CI}], 0.96-3.19 ; P=0.065$ ) favoring ${ }^{223} \mathrm{Ra}$ when adjusted for baseline covariates. The median relative change in PSA from baseline to 4 weeks after the last injection was $-23.8 \%$ in the ${ }^{223} \mathrm{Ra}$ group versus $+44.9 \%$ in the placebo group $(P=0.003)$. Confirmed PSA responses by PSA Working Group criteria ${ }^{53}$ ( $\geq 50 \%$ decline) were observed in eleven of 31 (35\%) patients on the ${ }^{223} \mathrm{Ra}$ arm and five of $28(18 \%)$ on the placebo arm $(P=0.153)$, with median time to PSA progression of 26 weeks and 8 weeks, respectively, on each $\operatorname{arm}(P=0.048)$. Notably, censoring for concomitant treatments did not substantially change the overall results. The median overall survival was 65.3 weeks for the ${ }^{223} \mathrm{Ra}$ group versus 46.4 weeks for placebo $(P=0.066)$, with an adjusted HR of 2.12 (95\% CI, 1.13-3.98; $P=0.020)$ favoring ${ }^{223} \mathrm{Ra}$. These survival results have been updated and remain similar with longer follow-up. ${ }^{54}$ Post hoc analyses showed OS of all patients to be 102.4 versus 42.6 weeks $(P<0.001)$ for posttreatment normalized versus nonnormalized from baseline ALP values, respectively; patients on the ${ }^{223} \mathrm{Ra}$ arm had OS of 102.1 versus 42.5 weeks $(P<0.001)$ for posttreatment normalized versus nonnormalized from baseline ALP values, respectively. ${ }^{55}$ In summary, this randomized, placebo-controlled study showed that repeat dosing of ${ }^{223} \mathrm{Ra}$ every 4 weeks is well tolerated in men with mCRPC and has a significant effect on bone ALP 4 weeks after finishing treatment, in addition to potential beneficial efficacy in terms of SREs, PSA, and overall survival end points.

The second study (BC1-03), a double-blind, randomized, dose-ranging study, was designed to examine the effect of a single injection of ${ }^{223} \mathrm{Ra}$ at $5,25,50$, or $100 \mathrm{kBq} / \mathrm{kg}$ in patients with progressive $\mathrm{mCRPC}$ and pain. ${ }^{52}$ Patients were required to have testosterone levels $<50 \mathrm{ng} / \mathrm{dL}$ after castration therapy, a score of $\geq 2$ on the BPI, ${ }^{56}$ progression of disease based on rising PSA levels, and sites of clinical pain correlating with multifocal osteoblastic disease on bone scintigraphy. The primary end point was the change in "pain index" (derived from a combination of the Visual Analogue Scale and analgesic consumption categorized according to the World Health Organization [WHO] analgesic ladder ${ }^{57}$ ) at weeks $2,4,8,12$, and 16 . Secondary end points included change from baseline in the BPI severity index and functional index, overall survival, duration of pain relief, relative change in bone ALP and PSA, and assessment of AEs.

One hundred patients were randomized and treated at 16 centers in Sweden, Germany, France, and the UK. ${ }^{52}$ Over half of patients had $>20$ bone lesions or a superscan, 
$81 \%$ had performance status of $0-1,36 \%$ had prior docetaxel, and $48 \%$ had a baseline WHO level of analgesia of 3 ; median baseline Visual Analogue Scale was $42 \mathrm{~mm}$. A statistically significant dose response for pain index was observed at week 2 only $(P=0.035)$. At week 8 , the percentage of pain responders was $40 \%, 63 \%, 56 \%$ and $71 \%$ on the 5,25 , 50 , and $100 \mathrm{kBq} / \mathrm{kg}$ arms, respectively. The BPI data also showed a significant dose response at week 8 for the Pain Severity Index $(P=0.040)$. In a post hoc analysis of pain responders, pain decreased by a mean of $-30,-31,-27$, and $-28 \mathrm{~mm}(P=0.008, P=0.0005, P=0.002$, and $P<0.0001)$. Furthermore, these responders showed an improvement in the BPI functional interference index in all groups. There were no differences in AEs among the dose groups, with the most frequent nonhematologic AEs being nausea, fatigue, vomiting, diarrhea, constipation, bone pain, urinary tract infection, and peripheral edema. In the two highest-dose groups, there appeared to be slightly greater reductions in platelet, leukocyte, and neutrophil counts. Nadir counts generally occurred at 2 weeks postinjection and subsequently returned to baseline. Changes in bone ALP were significant only in the $100-\mathrm{kBq} / \mathrm{kg}$ dose group at weeks 4 and 8 ( $P<0.0001$ and $P=0.0067$, respectively), whereas PSA increased from baseline to week 16 in all dose groups. The median overall survival for the study population was 50 weeks and did not significantly differ among groups.

Overall, this study focusing on the pain-relieving effects of a single injection of ${ }^{223} \mathrm{Ra}$ in escalating doses demonstrated an early dose response at week 2 and a maximum of $71 \%$ pain response at week 8 at the highest dose level. A well-tolerated safety profile was observed, although there were no effects on PSA levels and only a significant effect on bone ALP at the highest dose level. Notably, there may have been a problem with dropout bias, as 17 patients had dropped out by week 8 and there was differential dropout in the low- versus high-dose groups (eleven versus six patients).

A third randomized, double-blind dose-finding Phase II study of ${ }^{223} \mathrm{Ra}$ (BC1-04) has only been reported in abstract form. ${ }^{54,57}$ Patients were randomized to 25,50 , or $80 \mathrm{kBq} / \mathrm{kg}$ every 6 weeks for 12 weeks (three total doses). The primary end point was PSA response ( $\geq 50 \%$ decline from baseline). Bone markers, SREs, AEs, and survival were also evaluated. Sixty-one percent of patients had an elevated ALP at baseline. In these patients, normalization of ALP was associated with a significantly better survival compared with those who did not have normalization of ALP.

\section{Phase III study}

The results of the international, randomized, double-blind Alpharadin in Symptomatic Prostate Cancer (ALSYMPCA) Phase III trial were recently presented..$^{35}$ Eligible patients had confirmed symptomatic CRPC, two or more bone metastases, no known visceral metastases, and were either docetaxel-pretreated or unfit for docetaxel. Patients were randomized 2:1 to either ${ }^{223} \mathrm{Ra}$ injections at $50 \mathrm{kBq} / \mathrm{kg}$ with best standard of care or saline injections with best standard of care. Six injections were given at 4-week intervals. "Best supportive care" could include secondary hormonal therapies (antiandrogens, androgen biosynthesis inhibitors, steroids) or EBRT, but not cytotoxic chemotherapy or radioisotopes. Subjects were stratified according to total ALP, bisphosphonate use, and prior docetaxel treatment. The primary end point was overall survival, with secondary end points of time to first SRE, time to total ALP progression, total ALP response, total ALP normalization, time to PSA progression, safety, and quality of life. The trial was designed with $90 \%$ power to detect an HR of 0.76 with a two-sided alpha of 0.05 . Data from a planned interim analysis after 314 events from 809 randomized patients were presented. The trial was stopped based on the recommendation of an independent data-monitoring committee, due to early evidence of benefit in terms of overall survival (predetermined boundary crossed).

From June 2008 through February 2011, the investigators randomized 541 patients to ${ }^{223} \mathrm{Ra}$ and 268 patients to placebo (intention-to-treat group). ${ }^{35}$ The baseline characteristics between the arms appeared well matched, with baseline Eastern Cooperative Oncology Group (ECOG) $\leq 1$ in $86 \%$, 6-20 metastases in 44\%, and > 20 metastases/superscan in $40 \%$, and WHO ladder cancer pain index $\geq 2$ in $54 \%$ on the ${ }^{223} \mathrm{Ra}$ arm. About 58\% had received prior docetaxel. Median total ALP was $213 \mu \mathrm{g} / \mathrm{L}$, and PSA was $159 \mu \mathrm{g} / \mathrm{L}$ on the ${ }^{223} \mathrm{Ra}$ arm. Median overall survival was significantly improved in the ${ }^{223}$ Ra group compared with placebo: 14.0 versus 11.2 months (HR 0.695 [95\% CI, 0.552-0.875]; $P=0.00185$ ). In addition, time to first SRE was significantly improved in the ${ }^{223} \mathrm{Ra}$ arm: 13.6 versus 8.4 months (HR 0.610 [95\% CI, 0.461-0.807]; $P=0.00046)$. Significant improvements in the biochemical end points of time to total ALP progression (HR 0.163 [95\% CI, 0.121-0.221]; $P<0.00001)$, time to PSA progression (HR 0.671 [95\% CI, 0.546-0.826]; $P=0.00015$ ), total ALP response ( $43 \%$ vs $3 \% ; P<0.001)$, and total ALP normalization $(33 \%$ vs $1 \% ; P<0.001)$ were also observed.

Overall, ${ }^{223} \mathrm{Ra}$ appeared to be quite well tolerated. Notably, there were fewer AEs in the ${ }^{223} \mathrm{Ra}$ group than the placebo group as measured by all-grade AEs (88\% vs 94\%), 
grade 3 or 4 AEs ( $51 \%$ vs $59 \%$ ), serious AEs ( $43 \%$ vs $55 \%$ ), and discontinuation due to AEs (13\% vs $20 \%)$. The incidence of grade 3 or 4 neutropenia in the ${ }^{223}$ Ra group was $2 \%$ versus $1 \%$ in the placebo arm. Grade 3 or 4 thrombocytopenia was observed in $4 \%$ of subjects on the ${ }^{223} \mathrm{Ra}$ arm versus $2 \%$ on the placebo arm. All-grade AEs and grade 3 or 4 anemia were similar between arms. In terms of all-grade nonhematologic AEs, diarrhea (22\% vs $13 \%$ ) and vomiting (17\% vs $13 \%)$ appeared to be more frequent in the ${ }^{223}$ Ra group, whereas nausea (34\% vs 32\%) and constipation (18\% vs 18\%) appeared similar between groups.

Subgroup analysis demonstrated survival benefits across most clinically important patient subgroups, regardless of current use of bisphophonates, prior use of docetaxel, or ECOG performance status. ${ }^{35}$ One interesting result was that the HR appeared better in patients currently using bisphosphonates compared with those not on bisphosphonates. There is some biologic rationale for this effect, since the mechanism of action for bisphosphonates is inhibition of osteoclast activity. ${ }^{59}$ In theory, this decreased osteoclastic activity could result in ${ }^{223} \mathrm{Ra}$ having increased effect at sites of osteoblastic activity, due to longer binding times. ${ }^{35}$ It remains to be seen whether this effect would also be seen with denosumab, a monoclonal antibody against RANKL, but one might expect similar results. It would also be interesting to evaluate ${ }^{223} \mathrm{Ra}$ with agents known to elicit osteoblastic responses on bone scan, such as abiraterone acetate. ${ }^{60}$

More detailed results of the impact of ${ }^{223} \mathrm{Ra}$ on SREs were presented recently as well. ${ }^{61}$ In contrast to other trials of bone-targeted agents, ${ }^{16}$ no skeletal surveys were routinely performed during the ALSYMPCA trial; all imaging was performed only as clinically indicated. ${ }^{35}$ SRE components included pathologic bone fracture, spinal cord compression, EBRT, and surgical intervention. In addition to delaying time to first SRE (as mentioned above), ${ }^{223}$ Ra significantly delayed time to all SRE components except surgical intervention. ${ }^{61}$ EBRT was the most common SRE component: $23 \%$ vs $27 \%$ for the ${ }^{223} \mathrm{Ra}$ and placebo arms, respectively (HR 0.65 [95\% CI, 0.48-0.87]; $P=0.0038)$. Pathologic bone fracture was observed in 4\% vs 7\%, respectively (HR 0.45 [95\% CI, 0.24-0.86]; $P=0.013$ ). Of particular interest, spinal cord compression occurred in $3 \%$ of patients on the ${ }^{223} \mathrm{Ra}$ arm compared with $6 \%$ on placebo (HR 0.44 [95\% CI, 0.22-0.88]; $P=0.016)$. Although not common, this dreaded complication results in significant morbidity in men with advanced prostate cancer. ${ }^{62}$ This is the first study to demonstrate a significant effect on delay of spinal cord compression in this population.
At the time of this writing, no quality-of-life or painresponse data from the ALSYMPCA trial have been reported. Ideally, a therapy that prolongs OS and delays SREs, besides having biochemical effects, should do so with minimal compromise of quality of life and with improvements in pain. These results are eagerly awaited in order to confirm the benefit of ${ }^{223} \mathrm{Ra}$ in terms of patient-reported outcomes.

\section{Critical appraisal and potential role of ${ }^{223} \mathrm{Ra}$ in therapy of $\mathrm{mCRPC}$}

The pivotal Phase III randomized double-blind placebo controlled ALSYMPCA trial of ${ }^{223} \mathrm{Ra}$ demonstrated a highly significant OS improvement in docetaxel-pretreated or docetaxel-unfit men with symptomatic bone-metastatic CRPC and a very tolerable side-effect profile. A large number of men in the US with MCRPC are unfit for systemic chemotherapy due to toxicity concerns or comorbidities, and many men with mCRPC decline chemotherapy and all eventually fail first-line docetaxel. ${ }^{223} \mathrm{Ra}$ is pending regulatory approval in the US and abroad; however, based on recent FDA approvals in mCRPC based on overall survival benefits, ${ }^{5,12-14}$ approval of ${ }^{223} \mathrm{Ra}$ appears likely. Although time to first SRE was not the primary end point of the ALSYMPCA trial, the effects of ${ }^{223} \mathrm{Ra}$ on delaying SREs are important, and this end point has led to the regulatory approval of other bone-targeted agents even in the absence of beneficial effects on overall survival and disease progression. ${ }^{15,16}$ Based on eligibility criteria from this pivotal trial, it is likely that the label will be broad, encompassing both men with symptomatic bonemetastatic CRPC who have failed docetaxel and those who are not candidates for docetaxel chemotherapy.

The population of the ALSYMPCA trial was defined somewhat differently compared with prior trials in $\mathrm{MCRPC}$. Because docetaxel/prednisone was the first therapy proven to extend survival in men with $\mathrm{mCRPC}$ and therefore became the first-line standard of care, many contemporary trials have focused on either "pre-docetaxel" or "post-docetaxel" populations. More recent trials have also focused on "asymptomatic or minimally symptomatic" patients (eg, IMPACT, ${ }^{12}$ COU-AA-302, ${ }^{63}$ PREVAIL ${ }^{64}$ ). However, this is the first Phase III study of a survival-prolonging therapy to concentrate on the symptomatic, bone-metastatic subpopulation of mCRPC patients. Therefore, ${ }^{223} \mathrm{Ra}$ represents a unique treatment option in this subgroup. ${ }^{223} \mathrm{Ra}$ occupies a unique niche in that it prolongs OS, is a bone-targeted agent that delays SREs, and is also a radiopharmaceutical that might be expected to provide pain palliation (Phase III data not yet reported). 
${ }^{223} \mathrm{Ra}$ has not been compared head-to-head against other approved therapies in mCRPC. However, with this caveat and based on what is known from the fairly extensive study of ${ }^{223} \mathrm{Ra}$ in this population to date, the following observations can be made.

\section{Efficacy of ${ }^{223} \mathrm{Ra}$}

- A large and significant improvement in OS was observed when compared with placebo in men with MCRPC and symptomatic bony metastases. The concurrent demonstration of benefit in terms of delayed SREs and improvement in all biochemical end points (ie, PSA, total ALP), which would be expected with a therapy of ${ }^{223} \mathrm{Ra}$ 's mechanism of action, adds to the robustness of this finding.

- Subgroup analysis demonstrates that OS improvement was consistent across multiple clinically relevant subgroups. Importantly, these benefits were seen in prespecified groups (strata), including total ALP $<220 \mathrm{U} / \mathrm{L}$ and $\geq 220 \mathrm{U} / \mathrm{L}$; current bisphosphonate use (yes/no); or prior use of docetaxel (yes/no).

- The population of patients in the ALSYMPCA trial included both docetaxel-unfit and docetaxel-pretreated men. This makes cross-trial comparisons more difficult, since eligibility criteria for trials in $\mathrm{MCRPC}$ have historically focused on either chemonaive or chemo-pretreated populations. Men who are unfit for docetaxel-based chemotherapy may have a poorer survival relative to those who are chemotherapy candidates. ${ }^{65}$

- The reason for the choice of treatment with six total injections (or until progression of disease) is not clear, and could be an area for future study.

- Overall survival (Table 1):

- Cytotoxic chemotherapy: The absolute median OS difference of 2.8 months observed on the ALSYMPCA trial compares favorably with the 2.9-month difference seen in the chemonaive (but docetaxel-fit) population in the TAX-327 study ${ }^{66}$ and the $2.4-$ month difference in the docetaxel-pretreated population in the TROPIC study. ${ }^{13}$ However, it should be noted that both of these latter two trials used an active comparator (mitoxantrone plus prednisone ${ }^{10}$ ).

- AR-directed therapies: Trials with androgen receptor (AR)-directed therapies, such as abiraterone ${ }^{14}$ and MDV $3100,{ }^{17}$ in docetaxel-pretreated populations have demonstrated median OS differences of 4.6 and 4.8 months, respectively. Notably, these trials used the less active comparator of placebo plus prednisone. However, there is a strong rationale for combining these agents with ${ }^{223} \mathrm{Ra}$ based on the allowance of these classes of agents in the ALSYMPCA trial and the nonoverlapping toxicity profiles. Therefore, evaluation of combination versus sequential therapy with these agents should be encouraged.

- Radiopharmaceuticals: None of the currently FDA-approved radiopharmaceuticals (eg, ${ }^{89} \mathrm{Sr},{ }^{153} \mathrm{Sm}$ ) have demonstrated an OS benefit in a randomized Phase III study in men with mCRPC. ${ }^{11}$

- Antiresorptive agents: None of the currently FDAapproved osteoclast inhibitors (eg, zoledronic acid, denosumab) have demonstrated OS benefits over placebo. However, their use with ${ }^{223} \mathrm{Ra}$ is likely to be beneficial without overlapping toxicity based on the Phase III evidence to date.

- Skeletal-related events (Table 4):

- Cytotoxic chemotherapy: There is insufficient evidence to demonstrate that docetaxel and cabazitaxel prevent or delay SREs, although they are known to result in pain palliation and to prolong time to pain progression, disease progression, and overall survival.

- AR-directed therapies: Abiraterone has demonstrated delay in time to first SRE (25th percentile, 301 vs 150 days; $P<0.0001$ ) in the COU-AA-301 trial. ${ }^{20}$ Time to first SRE was a secondary end point in the

Table 4 Skeletal-related event (SRE) delay in recent Phase III trials of bone-targeted therapies in bone-metastatic mCRPC

\begin{tabular}{|c|c|c|c|c|c|}
\hline $\begin{array}{l}\text { Agent } \\
\text { (trial, year) }\end{array}$ & $\begin{array}{l}\text { Mechanism of } \\
\text { action }\end{array}$ & Disease state & Comparator & $\begin{array}{l}\text { Hazard } \\
\text { ratio }\end{array}$ & $\begin{array}{l}\text { Time to Ist SRE, months } \\
\text { (P-value) }\end{array}$ \\
\hline $\begin{array}{l}\text { Zoledronic acid } \\
(\text { Zometa 039, 2002) }\end{array}$ & $\begin{array}{l}\text { Bisphosphonate - } \\
\text { osteoclast inhibitor }\end{array}$ & $\begin{array}{l}\text { BM mCRPC, } \\
\text { asymptomatic }\end{array}$ & Placebo & 0.80 & $\begin{array}{l}13.8 \text { vs } 10.6 \\
(0.02)\end{array}$ \\
\hline Denosumab $(2010)^{16}$ & $\begin{array}{l}\text { RANK-L antibody - } \\
\text { osteoclast inhibitor }\end{array}$ & $\begin{array}{l}\text { BM mCRPC, } \\
\text { asymptomatic }\end{array}$ & Zoledronic acid & 0.82 & $\begin{array}{l}20.7 \text { vs } 17.1 \\
(0.008)\end{array}$ \\
\hline $\begin{array}{l}\text { Radium-223 } \\
(\text { ALSYMPCA) }\end{array}$ & $\begin{array}{l}\text { Radiopharmaceutical - } \\
\text { calcium mimic }\end{array}$ & $\begin{array}{l}\text { BM mCRPC, } \\
\text { symptomatic }\end{array}$ & Placebo + BSC* & 0.61 & $\begin{array}{l}\text { I3.6 vs } 8.4 \\
(0.00046)\end{array}$ \\
\hline
\end{tabular}

Note: *BSC included secondary hormonal therapies, external beam radiotherapy, and bisphosphonates (4l\%), but not cytotoxic chemotherapy or radiopharmaceuticals. Abbreviations: BM, bone-metastatic; mCRPC, metastatic castrate-resistant prostate cancer; BSC, best supportive care. 
AFFIRM trial of MDV3100 (NCT00974311), but this result has not yet been reported. ${ }^{17}$

- Radiopharmaceuticals: There is insufficient evidence to demonstrate that ${ }^{89} \mathrm{Sr}$ or ${ }^{153} \mathrm{Sm}$ prevent or delay SREs. ${ }^{11}$

- Antiresorptive agents: Zoledronic acid delays SREs compared with placebo, and denosumab is superior to zoledronic acid in delaying SREs in men with mCRPC. Notably, subgroup analysis of the ALSYMPCA trial suggested that bisphosphonates may potentiate the activity of ${ }^{223} \mathrm{Ra}$; a similar effect would be expected with denosumab, though there is a lack of data regarding this.

- Pain palliation was demonstrated in Phase III trials of docetaxel and abiraterone, but not cabazitaxel (Table 2). A key indication for the use of radioisotopes for men with $\mathrm{mCRPC}$ has been pain palliation, although there is likely only a small benefit in complete reduction of pain over 1-6 months and no increase in analgesic use (Table 5). ${ }^{11}$ Data on pain palliation from the ${ }^{223} \mathrm{Ra}$ Phase III ALSYMPCA trial have not been reported; however, the Phase I and II experience with ${ }^{223}$ Ra would suggest a benefit in terms of pain palliation.

\section{Safety and toxicity profile}

- The most common nonhematologic side effects of ${ }^{223} \mathrm{Ra}$ in the ALSYMPCA trial include diarrhea, nausea, vomiting, and constipation. Notably, nausea and constipation did not appear to be more frequent on the

${ }^{223} \mathrm{Ra}$ arm versus placebo. Two percent or fewer of these nonhematologic, gastrointestinal side effects were grade 3 or 4 . Overall, only about $10 \%$ of patients on the ${ }^{223} \mathrm{Ra}$ arm had grade $\geq 3$ AEs, fewer than on the placebo arm.

- Neutropenia and thrombocytopenia are side effects of ${ }^{223} \mathrm{Ra}$ and occurred overall in $4 \%$ and $8 \%$, respectively, of patients in the ALSYMPCA trial. Grade 3 or 4 neutropenia and thrombocytopenia were observed in $2 \%$ and $4 \%$, respectively.

- In contrast with other radioisotopes, ${ }^{223} \mathrm{Ra}$ appears to have much less myelosuppression. This property allows consecutive doses to be administered safely, and may be the basis for its more substantial antitumor effects and

Table 5 Radiopharmaceuticals in selected randomized trials in men with prostate cancer

\begin{tabular}{|c|c|c|c|c|c|}
\hline Trial, dose & Comparator & Overall survival & Pain palliation & Key side effects & Comments \\
\hline \multicolumn{6}{|l|}{ Strontium-89 } \\
\hline $\begin{array}{l}\text { Canadian } \\
400 \mathrm{MBq} \times \mathrm{I} \text { adjunct to RT } \\
(\mathrm{n}=126)^{25}\end{array}$ & Placebo & No difference & No difference & $\begin{array}{l}\text { Increased hematologic } \\
\text { toxicity with }{ }^{89} \mathrm{Sr}\end{array}$ & $\begin{array}{l}\text { Differences in pain } \\
\text { progression, PSA, ALP, } \\
\text { QoL favoring }{ }^{89} \mathrm{Sr}\end{array}$ \\
\hline $\begin{array}{l}\text { British } \\
200 \mathrm{MBq} \times 1 \\
(\mathrm{n}=284)^{26}\end{array}$ & $\begin{array}{l}\text { EBRT } \\
(\mathrm{F} \text { or } \mathrm{HB})\end{array}$ & No difference* & No difference ${ }^{\dagger}$ & $\begin{array}{l}\downarrow W B C \text { and } \downarrow \text { PLT by } \\
30 \%-40 \% \text { with }{ }^{89} \mathrm{Sr}\end{array}$ & $\begin{array}{l}\mathrm{RT} \text { to new site less frequent } \\
\text { with }{ }^{89} \mathrm{Sr}(P<0.0 \mathrm{I})\end{array}$ \\
\hline $\begin{array}{l}\text { EORTC } \\
\text { I50 MBq } \times \text { I } \\
(\mathrm{n}=203)^{27}\end{array}$ & Local field RT & $\begin{array}{l}\mathrm{RT} \text { superior } \\
\text { vs }{ }^{89} \mathrm{Sr}^{\ddagger}\end{array}$ & No difference ${ }^{\S}$ & $\begin{array}{l}\text { No difference between } \\
\text { groups }\end{array}$ & $\begin{array}{l}\text { No difference in PFS or } \\
\text { TTP; PSA responses in } \\
10 \%-13 \%\end{array}$ \\
\hline \multicolumn{6}{|l|}{ Samarium-I53 } \\
\hline $\begin{array}{l}\text { Serafini et al } \\
0.5 \text { or } 1.0 \mathrm{mCi} / \mathrm{kg} \times 1 \\
(\mathrm{n}=118 ; 68 \% \mathrm{PC})^{28}\end{array}$ & Placebo & No difference & $\begin{array}{l}\text { Only with } 1.0 \mathrm{mCi} / \\
\mathrm{kg} \text { dose }\end{array}$ & $\begin{array}{l}\text { Mean } W B C \text { and PLT nadirs } \\
3100 / \mu \mathrm{L} \text { and } 118,000 / \mu \mathrm{L} \\
\text { with } 1.0 \mathrm{mCi} / \mathrm{kg}^{\prime \prime}\end{array}$ & $\begin{array}{l}72 \% \text { and } 43 \% \text { pain relief } \\
\text { at } 4 \text { and } 12 \text { weeks with } \\
1.0 \mathrm{mCi} / \mathrm{kg}\end{array}$ \\
\hline $\begin{array}{l}\text { Sartor et al } \\
1.0 \mathrm{mCi} / \mathrm{kg} \times 1 \\
(\mathrm{n}=152)^{29}\end{array}$ & Placebo & No difference & $\begin{array}{l}\text { Significant reduction } \\
\text { within I-2 weeks } \\
\text { lasting to } 4 \text { weeks** }\end{array}$ & $\begin{array}{l}\text { Mean } W B C \text { and PLT nadirs } \\
3800 / \mu \mathrm{L} \text { and } 127,000 / \mu \mathrm{L} \\
\text { with }{ }^{153} \mathrm{Sm}^{+\dagger}\end{array}$ & $\begin{array}{l}\text { Significant reductions } \\
\text { in opioid use at } 3 \text { and } \\
4 \text { weeks with }{ }^{153} \mathrm{Sm} \text {; } \\
\text { retreatment feasible }{ }^{29}\end{array}$ \\
\hline \multicolumn{6}{|l|}{ Radium-223 } \\
\hline $\begin{array}{l}\text { ALSYMPCA } \\
50 \mathrm{kBq} / \mathrm{kg} \times 6 \\
(\mathrm{n}=809)^{35}\end{array}$ & Placebo & $\begin{array}{l}\text { I } 4.0 \text { vs } \\
\text { II. } 2 \text { months } \\
(P=0.00 \mid 85)\end{array}$ & Not reported & $\begin{array}{l}\text { Diarrhea, vomiting; } \\
\text { grade } \geq 3 \text { ANC ( } 2 \%) \\
\text { and PLT }(4 \%)\end{array}$ & $\begin{array}{l}\text { Significant delay in } \mathrm{SREs}^{58} \\
\text { and improvements in } \\
\text { PSA and ALP }\end{array}$ \\
\hline
\end{tabular}

Notes: $* 33$ vs 28 weeks for ${ }^{89} \mathrm{Sr}$ vs RT $(P=0.1)$; ${ }^{\dagger}$ sustained relief in two-thirds at 12 weeks, all 3 treatments provided similarly effective pain relief; ${ }^{\ddagger}$ I vs 7 months for RT

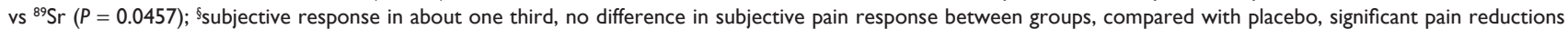
at $1.0 \mathrm{mCi} / \mathrm{kg}$, but not $0.5 \mathrm{mCi} / \mathrm{kg}$, at I and 4 weeks; " ${ }^{\circ}$ compared with placebo, significant pain reductions at $1.0 \mathrm{mCi} / \mathrm{kg}$, but not $0.5 \mathrm{mCi} / \mathrm{kg}$, at I and $4 \mathrm{weeks}$; "no grade 4 hematologic toxicity observed, complete recovery of myelosuppresion by 8 weeks; ${ }^{* *}$ placebo-treated patients could cross over to receive ${ }^{153} \mathrm{Sm}$ after 4 weeks; ${ }^{\dagger+}$ counts generally recovered by 8 weeks.

Abbreviations: MBq, megabecquerel; RT, radiotherapy; PSA, prostate-specific antigen; ALP, alkaline phosphatase; QoL, quality of life; EBRT, external beam radiotherapy; F, focal; HB, hemibody; ${ }^{89} \mathrm{Sr}$, strontium-89; EORTC, European Organization for Research and Treatment of Cancer; PFS, progression-free survival; TTP, time to progression; $\mathrm{mCi}$, millicurie; PC, prostate cancer; ANC, absolute neutrophil count; PLT, platelets; SRE, skeletal-related event. 
OS compared with $\beta$-emitters. Additionally, with ${ }^{223} \mathrm{Ra}$, neutropenia predominates over thrombocytopenia, which is the inverse of the pattern seen with $\beta$-emitters.

- Judged against cytotoxic chemotherapies, ${ }^{223} \mathrm{Ra}$ is likely to have a significantly better toxicity profile in terms of myelosuppression and gastrointestinal and other side effects. In an extreme example, in the TROPIC trial of cabazitaxel, grade 3 or 4 diarrhea was observed in $6.2 \%$ and grade 3 or 4 neutropenia in $81.7 \%$ (febrile neutropenia $7.5 \%$ ).

- In comparison to AR-directed therapies, ${ }^{223} \mathrm{Ra}$ has a distinct toxicity profile but may be similarly tolerable. Patients treated with abiraterone acetate have demonstrated side effects related to mineralocorticoid excess due to the drug's mechanism of action, such as fluid retention, hypertension, and hypokalemia. ${ }^{14}$ The most common side effect overall and grade 3 or 4 side effect observed with MDV3100 was fatigue, with patients rarely experiencing seizures $(0.6 \%$; all grade $\geq 3) .{ }^{17}$

- Antiresorptive agents are likely to be used in combination with ${ }^{223} \mathrm{Ra}$, as in the Phase III trial, and side effects generally appear to be nonoverlapping.

- Data on quality of life with ${ }^{223} \mathrm{Ra}$ from the ALSYMPCA trial are eagerly awaited.

- In comparison to $\beta$-emitters, which are renally excreted, ${ }^{223} \mathrm{Ra}$ is eliminated via the small intestine. This could be an important advantage in patients with mCRPC.

- Long-term safety data with ${ }^{223} \mathrm{Ra}$ are lacking. However, there is extensive experience with ${ }^{224} \mathrm{Ra}$ in patients with ankylosing spondylitis. ${ }^{42}$ An increased risk for later cancers has been observed, but only in individuals treated with ${ }^{224} \mathrm{Ra}$ as children and, importantly, not in those treated as adults. ${ }^{67}$ In comparison, there have been reports of acute leukemia with ${ }^{89} \mathrm{Sr}$ but not ${ }^{153} \mathrm{Sm} .{ }^{68}$

\section{Future directions}

Emerging therapies aimed at preventing skeletal morbidity in men with prostate cancer have recently been reviewed in detail. ${ }^{69}$ Notable bone-targeted therapies in clinical development for mCRPC include SRC-targeted therapies (dasatinib), and MET-targeted therapies. While the oral endothelin (ETA) receptor antagonists atrasentan and zibotentan (ZD4054) were not successful in Phase III trials when combined with docetaxel in mCRPC, it is possible that these agents may combine favorably with other bone-targeted strategies. The oral SRC tyrosine kinase inhibitor dasatinib (Sprycel; BristolMyers Squibb, New York, NY) is being evaluated in a Phase III mCRPC trial of docetaxel/prednisone with dasatinib or placebo (NCT00744497), ${ }^{70}$ with results anticipated in 2012.
Finally, the multitargeted tyrosine kinase inhibitor XL-184 (cabozantinib), which inhibits MET, VEFGR2, RET, and Kit, has shown impressive results in a Phase II study ${ }^{71}$ and will enter Phase III testing soon. ${ }^{72,73}$

Beta emitters have been combined with chemotherapy in several studies, including two randomized studies, demonstrating the possible feasibility and safety of this approach. ${ }^{31-34}$ For example, one recent Phase I study by Morris et al demonstrated that docetaxel and ${ }^{153} \mathrm{Sm}$ could be administered at full doses over repeated cycles. ${ }^{31}$ Given the improved toxicity profile with ${ }^{223} \mathrm{Ra}$ over $\beta$-emitters, it seems likely that ${ }^{223} \mathrm{Ra}$ could be combined with chemotherapy as well. This concept is currently being investigated in a Phase I/II trial of ${ }^{223} \mathrm{Ra}$ with docetaxel chemotherapy in men with bone metastasis from CRPC (NCT01106352).${ }^{74}$ As a synergistic interaction between androgen-deprivation therapy and radiotherapy that increases apoptosis is known to exist in prostate cancer, ${ }^{75}$ it is conceivable that this synergy could exist between ${ }^{223} \mathrm{Ra}$ and the newer AR-directed therapies (eg, abiraterone, MDV3100) as well. Finally, it is possible that

${ }^{223} \mathrm{Ra}$ and bone-targeted agents in development could have complementary mechanisms of action. All of these remain important research questions that should be addressed in the near future.

\section{Conclusion}

The overall risk-to-benefit ratio of ${ }^{223} \mathrm{Ra}$ appears quite favorable. The available data demonstrate that ${ }^{223} \mathrm{Ra}$ has activity in men with symptomatic bone-metastatic CRPC who are either docetaxel-unfit or docetaxel-pretreated. The significant improvement in median OS is an acceptable surrogate of clinical benefit, and is bolstered by delay of SREs and improvement in biochemical end points. These benefits are in the range observed with other approved therapies in this setting. When examined in the context of ${ }^{223} \mathrm{Ra}$-associated toxicity, these benefits appear well worth the risk in the subpopulation of patients included in the ALSYMPCA trial. Side effects were mild and predominantly gastrointestinal (diarrhea and vomiting). Myelosuppression was minimal, with rare grade $\geq 3$ neutropenia and thrombocytopenia. Toxicities appear to be less than those with cytotoxic chemotherapies and are similarly mild, though distinct, when compared to AR-directed therapies. Significantly less myelosuppression is observed with ${ }^{223} \mathrm{Ra}$ compared with $\beta$-emitters. The effects of ${ }^{223} \mathrm{Ra}$ on quality of life and pain palliation from the randomized Phase III trial have not been reported. In clinical practice, it is likely that ${ }^{223} \mathrm{Ra}$ would be used in conjunction with antiresorptive agents. Compared 
with approved cytotoxic chemotherapies, AR-directed therapies, and other radioisotopes, ${ }^{223} \mathrm{Ra}$ could occupy a unique niche in the treatment of $\mathrm{mCRPC}$.

\section{Disclosure}

Consultant or advisory roles: Michael R Harrison, Exelixis; Andrew J Armstrong, Sanofi, Bayer, Dendreon, Amgen, Medivation, Janssen, Active Biotech, Bristol-Myers Squibb; Daniel J George, Astellas, Aveo, Bayer, Dendreon, Exelixis, Genentech, Medivation, Novartis, Pfizer, Sanofi, Viamet. Honoraria (speaking): Andrew J Armstrong, Sanofi, Dendreon, Amgen; Daniel J George, Amgen, Dendreon, Novartis, Pfizer, Sanofi. Research funding: Michael R Harrison, Exelixis; Andrew J Armstrong, Sanofi-Aventis, Dendreon, Medivation, Janssen, Active Biotech, Imclone/ Eli Lilly, Novartis, Bristol-Myers Squibb; Daniel J George, Exelixis, Genentech, GSK, Millennium, Novartis, Pfizer. Terence $\mathrm{Z}$ Wong reports no conflicts of interest in this work.

\section{References}

1. Siegel R, Naishadham D, Jemal A. Cancer statistics, 2012. CA Cancer J Clin. 2012;62(1):10-29.

2. Josson S, Matsuoka Y, Chung LW, Zhau HE, Wang R. Tumor-stroma co-evolution in prostate cancer progression and metastasis. Semin Cell Dev Biol. 2010;21(1):26-32.

3. Armstrong AJ, Marengo MS, Oltean S, et al. Circulating tumor cells from patients with advanced prostate and breast cancer display both epithelial and mesenchymal markers. Mol Cancer Res. 2011;9(8):997-1007.

4. Petrylak DP, Tangen CM, Hussain MH, et al. Docetaxel and estramustine compared with mitoxantrone and prednisone for advanced refractory prostate cancer. $N$ Engl J Med. 2004;351(15):1513-1520.

5. Tannock IF, de Wit R, Berry WR, et al. Docetaxel plus prednisone or mitoxantrone plus prednisone for advanced prostate cancer. $N$ Engl J Med. 2004;351(15):1502-1512.

6. Armstrong AJ, Garrett-Mayer ES, Yang YC, de Wit R, Tannock IF, Eisenberger M. A contemporary prognostic nomogram for men with hormone-refractory metastatic prostate cancer: a TAX327 study analysis. Clin Cancer Res. 2007;13(21):6396-6403.

7. Armstrong AJ, Garrett-Mayer E, Ou Yang YC, et al. Prostate-specific antigen and pain surrogacy analysis in metastatic hormone-refractory prostate cancer. J Clin Oncol. 2007;25(25):3965-3970.

8. Armstrong AJ, Garrett-Mayer E, de Wit R, Tannock I, Eisenberger M. Prediction of survival following first-line chemotherapy in men with castration-resistant metastatic prostate cancer. Clin Cancer Res. 2010; 16(1):203-211.

9. Halabi S, Vogelzang NJ, Kornblith AB, et al. Pain predicts overall survival in men with metastatic castration-refractory prostate cancer. J Clin Oncol. 2008;26(15):2544-2549.

10. Tannock IF, Osoba D, Stockler MR, et al. Chemotherapy with mitoxantrone plus prednisone or prednisone alone for symptomatic hormone-resistant prostate cancer: a Canadian randomized trial with palliative end points. J Clin Oncol. 1996;14(6):1756-1764.

11. Roque IFM, Martinez-Zapata MJ, Scott-Brown M, Alonso-Coello P. Radioisotopes for metastatic bone pain. Cochrane Database Syst Rev. 2011;7:CD003347.

12. Kantoff PW, Higano CS, Shore ND, et al. Sipuleucel-T immunotherapy for castration-resistant prostate cancer. $N$ Engl J Med. 2010;363(5):411-422.
13. de Bono JS, Oudard S, Ozguroglu M, et al. Prednisone plus cabazitaxel or mitoxantrone for metastatic castration-resistant prostate cancer progressing after docetaxel treatment: a randomised open-label trial. Lancet. 2010;376(9747):1147-1154.

14. de Bono JS, Logothetis CJ, Molina A, et al. Abiraterone and increased survival in metastatic prostate cancer. N Engl J Med. 2011;364(21): 1995-2005.

15. Saad F, Gleason DM, Murray R, et al. A randomized, placebo-controlled trial of zoledronic acid in patients with hormone-refractory metastatic prostate carcinoma. J Natl Cancer Inst. 2002;94(19):1458-1468.

16. Fizazi K, Carducci M, Smith M, et al. Denosumab versus zoledronic acid for treatment of bone metastases in men with castrationresistant prostate cancer: a randomised, double-blind study. Lancet. 2011;377(9768):813-822

17. Scher HI, Fizazi K, Saad F, et al. Effect of MDV3100, an androgen receptor signaling inhibitor (ARSI), on overall survival in patients with prostate cancer postdocetaxel: Results from the phase III AFFIRM study. J Clin Oncol. 2012;30(Suppl 5):Abstr LBA1.

18. de Bono J, Fizazi K, Saad F, et al. Primary, secondary, and quality-oflife endpoint results from the phase III AFFIRM study of MDV3100, an androgen receptor signaling inhibitor. J Clin Oncol. 2012; 30(Suppl):Abstr 4519^.

19. Enzalutamide (XTANDI Capsules) [webpage on the Internet]. Silver Spring, MD: US Food and Drug Administration; 2012 [updated September 4, 2012]. Available from: http://www.fda.gov/Drugs/InformationOnDrugs/ApprovedDrugs/ucm317997.htm. Accessed December 12, 2012.

20. Logothetis C, De Bono JS, Molina A, et al. Effect of abiraterone acetate (AA) on pain control and skeletal-related events (SRE) in patients (pts) with metastatic castration-resistant prostate cancer (mCRPC) post docetaxel (D): Results from the COU-AA-301 phase III study. $J$ Clin Oncol. 2011;29(Suppl):Abstr 4520.

21. Saad F, Gleason DM, Murray R, et al. Long-term efficacy of zoledronic acid for the prevention of skeletal complications in patients with metastatic hormone-refractory prostate cancer. $J$ Natl Cancer Inst. 2004;96(11):879-882.

22. Adam A, Dixon AK, Allison DJ, Grainger RG. Grainger and Allison's Diagnostic Radiology: a Textbook of Medical Imaging, 5th ed. Edinburgh: Churchill Livingstone; 2008.

23. Lewington VJ, McEwan AJ, Ackery DM, et al. A prospective, randomised double-blind crossover study to examine the efficacy of strontium-89 in pain palliation in patients with advanced prostate cancer metastatic to bone. Eur J Cancer. 1991;27(8):954-958.

24. Buchali K, Correns HJ, Schuerer M, Schnorr D, Lips H, Sydow K. Results of a double blind study of 89-strontium therapy of skeletal metastases of prostatic carcinoma. Eur J Nucl Med. 1988;14(7-8): 349-351.

25. Porter AT, McEwan AJ, Powe JE, et al. Results of a randomized phase-III trial to evaluate the efficacy of strontium- 89 adjuvant to local field external beam irradiation in the management of endocrine resistant metastatic prostate cancer. Int J Radiat Oncol Biol Phys. 1993;25(5):805-813.

26. Quilty PM, Kirk D, Bolger JJ, et al. A comparison of the palliative effects of strontium- 89 and external beam radiotherapy in metastatic prostate cancer. Radiother Oncol. 1994;31(1):33-40.

27. Oosterhof GO, Roberts JT, de Reijke TM, et al. Strontium(89) chloride versus palliative local field radiotherapy in patients with hormonal escaped prostate cancer: a phase III study of the European Organisation for Research and Treatment of Cancer, Genitourinary Group. Eur Urol. 2003;44(5):519-526.

28. Serafini AN, Houston SJ, Resche I, et al. Palliation of pain associated with metastatic bone cancer using samarium-153 lexidronam: a double-blind placebo-controlled clinical trial. JClin Oncol. 1998;16(4): 1574-1581.

29. Sartor O, Reid RH, Hoskin PJ, et al. Samarium-153-Lexidronam complex for treatment of painful bone metastases in hormone-refractory prostate cancer. Urology. 2004;63(5):940-945. 
30. Sartor O, Reid RH, Bushnell DL, Quick DP, Ell PJ. Safety and efficacy of repeat administration of samarium Sm-153 lexidronam to patients with metastatic bone pain. Cancer. 2007;109(3):637-643.

31. Morris MJ, Pandit-Taskar N, Carrasquillo J, et al. Phase I study of samarium-153 lexidronam with docetaxel in castration-resistant metastatic prostate cancer. J Clin Oncol. 2009;27(15):2436-2442.

32. Tu SM, Millikan RE, Mengistu B, et al. Bone-targeted therapy for advanced androgen-independent carcinoma of the prostate: a randomised phase II trial. Lancet. 2001;357(9253):336-341.

33. Sciuto R, Festa A, Rea S, et al. Effects of low-dose cisplatin on $89 \mathrm{Sr}$ therapy for painful bone metastases from prostate cancer: a randomized clinical trial. J Nucl Med. 2002;43(1):79-86.

34. Fizazi K, Beuzeboc P, Lumbroso J, et al. Phase II trial of consolidation docetaxel and samarium-153 in patients with bone metastases from castration-resistant prostate cancer. J Clin Oncol 2009;27(15):2429-2435.

35. Parker C, Heinrich D, O'Sullivan JM, et al. Overall survival benefit and safety profile of radium-223 chloride, a first-in-class alphapharmaceutical: results from a phase III randomized trial (ALSYMPCA) in patients with castration-resistant prostate cancer (CRPC) with bone metastases. J Clin Oncol. 2012;30(Suppl 5):Abstr 8.

36. Bayer. Radium-223 Chloride (Alpharadin) in Castration-Resistant (Hormone-Refractory) Prostate Cancer Patients with Bone Metastases. In: ClinicalTrials.gov [website on the Internet]. Bethesda, MD: US National Library of Medicine; 2012 [updated September 20, 2012]. Available from: http://clinicaltrials.gov/show/NCT01516762. NLM identifier: NCT01516762. Accessed November 1, 2012.

37. Perez CA. Principles and Practice of Radiation Oncology, 4th ed. Philadelphia: Lippincott Williams \& Wilkins; 2004.

38. Bruland ØS, Nilsson S, Fisher DR, Larsen RH. High-linear energy transfer irradiation targeted to skeletal metastases by the alpha-emitter 223Ra: adjuvant or alternative to conventional modalities? Clin Cancer Res. 2006;12(20 Pt 2):6250s-6257s.

39. Blake GM, Gray JM,Zivanovic MA, McEwan AJ, Fleming JS, Ackery DM. Strontium-89 radionuclide therapy: a dosimetric study using impulse response function analysis. Br J Radiol. 1987;60(715):685-692.

40. Breen SL, Powe JE, Porter AT. Dose estimation in strontium- 89 radiotherapy of metastatic prostatic carcinoma. J Nucl Med. 1992;33(7) 1316-1323.

41. ASBMR educational materials [webpage on the Internet]. Bone curriculum. Available from: http://depts.washington.edu/bonebio/ ASBMRed/ASBMRed.html. American Society of Bone and Mineral Research [updated 2008]. Accessed July 26, 2012.

42. Tiepolt C, Gruning T, Franke WG. Renaissance of 224 Ra for the treatment of ankylosing spondylitis: clinical experiences. Nucl Med Commun. 2002;23(1):61-66.

43. Nilsson S, Larsen RH, Fossa SD, et al. First clinical experience with alpha-emitting radium-223 in the treatment of skeletal metastases. Clin Cancer Res. 2005;11(12):4451-4459.

44. Ritter MA, Cleaver JE, Tobias CA. High-LET radiations induce a large proportion of non-rejoining DNA breaks. Nature. 1977;266(5603): 653-655.

45. Hall EJ, Giaccia AJ. Radiobiology for the Radiologist, 6th ed. Philadelphia: Lippincott Williams \& Wilkins; 2006.

46. Henriksen G, Fisher DR, Roeske JC, Bruland OS, Larsen RH. Targeting of osseous sites with alpha-emitting 223Ra: comparison with the beta-emitter $89 \mathrm{Sr}$ in mice. $J$ Nucl Med. 2003;44(2): 252-259.

47. Henriksen G, Breistol K, Bruland OS, Fodstad O, Larsen RH. Significant antitumor effect from bone-seeking, alpha-particle-emitting (223)Ra demonstrated in an experimental skeletal metastases model. Cancer Res. 2002;62(11):3120-3125.

48. Smeland S, Erikstein B, Aas M, Skovlund E, Hess SL, Fossa SD. Role of strontium- 89 as adjuvant to palliative external beam radiotherapy is questionable: results of a double-blind randomized study. Int $J$ Radiat Oncol Biol Phys. 2003;56(5):1397-1404.
49. Nilsson S, Balteskard L, Fossa SD, et al. Phase I study of Alpharadin2 (223Ra), and a-emitting bone-seeking agent in cancer patients with skeletal metastases. EurJ Nucl Med Mol Imaging. 2004;31(S2):S290, Abstract 370.

50. Carrasquillo JA, Donoghue JAO, Pandit-Taskar N, et al. Phase I pharmacokinetic (PK) and biodistribution study of radium-223 chloride in patients with castration resistant prostate cancer (CRPC) metastatic to bone. J Clin Oncol. 2010;28(15s):Abstr 4680.

51. Nilsson S, Franzen L, Parker C, et al. Bone-targeted radium-223 in symptomatic, hormone-refractory prostate cancer: a randomised, multicentre, placebo-controlled phase II study. Lancet Oncol. 2007;8(7):587-594.

52. Nilsson S, Strang P, Aksnes AK, et al. A randomized, dose-response, multicenter phase II study of radium-223 chloride for the palliation of painful bone metastases in patients with castration-resistant prostate cancer. Eur J Cancer. 2012;48(5):678-686.

53. Bubley GJ, Carducci M, Dahut W, et al. Eligibility and response guidelines for phase II clinical trials in androgen-independent prostate cancer: recommendations from the Prostate-Specific Antigen Working Group. J Clin Oncol. 1999;17(11):3461-3467.

54. Nilsson S, Franzén L, Parker C, et al. Alpha-emitting radium-223: Two years follow up from a randomized phase II study in patients with bone metastases from hormone refractory prostate cancer. Eur J Cancer Suppl. 2009;7:411(Abstract P-7018).

55. Nilsson S, O'Bryan-Tear CG, Bolstad B, Lokna A, Parker C. Alkaline phosphatase (ALP) normalization and overall survival in patients with bone metastases from castration-resistant prostate cancer (CRPC) treated with Radium-223 (Alpharadin ${ }^{\mathrm{TM}}$ ). J Clin Oncol. 2011;29(Suppl): Abstr $4620^{\wedge}$

56. Cleeland CS, Ryan KM. Pain assessment: global use of the Brief Pain Inventory. Ann Acad Med Singapore. 1994;23(2):129-138.

57. Palliative Care: Symptom Management and End-of-Life Care. Geneva: World Health Organization; 2004. Available from: http://www.who. int $/ 3$ by $5 /$ publications/documents/en/genericpalliativecare082004.pdf. Accessed.

58. Algeta ASA. A Dose Finding Study of Radium-223 for Prostate Cancer Patients with Bone Metastases. In: ClinicalTrials.gov [website on the Internet]. Bethesda, MD: US National Library of Medicine; 2012 [updated September 8, 2010]. Available from: http://clinicaltrials.gov/ ct2/show/NCT00337155. NLM identifier: NCT00337155. Accessed November 1, 2012.

59. Fleisch H. Bisphosphonates: mechanisms of action. Endocr Rev. 1998 ; 19(1):80-100.

60. Ryan CJ, Shah S, Efstathiou E, et al. Phase II study of abiraterone acetate in chemotherapy-naive metastatic castration-resistant prostate cancer displaying bone flare discordant with serologic response. Clin Cancer Res. 2011;17(14):4854-4861.

61. Sartor AO, Heinrich D, Helle SI, et al. Radium-223 chloride impact on skeletal-related events in patients with castration-resistant prostate cancer (CRPC) with bone metastases: A phase III randomized trial (ALSYMPCA). J Clin Oncol. 2012;30(Suppl 5):Abstr 9.

62. Loblaw A, Mitera G. Malignant extradural spinal cord compression in men with prostate cancer. Curr Opin Support Palliat Care. 2011;5(3):206-210.

63. Ryan CJ, Smith MR, De Bono JS, et al. Interim analysis (IA) results of COU-AA-302, a randomized, phase III study of abiraterone acetate (AA) in chemotherapy-naive patients (pts) with metastatic castration-resistant prostate cancer (mCRPC). J Clin Oncol. 2012;30(Suppl): Abstr LBA4518.

64. Medivation Inc. A Safety and Efficacy Study of Oral MDV3100 in Chemotherapy-Naive Patients with Progressive Metastatic Prostate Cancer (PREVAIL). In: ClinicalTrials.gov [website on the Internet]. Bethesda, MD: US National Library of Medicine; 2012 [updated October 11, 2012]. Available from: http://clinicaltrials.gov/show/NCT01212991. NLM identifier: NCT01212991. Accessed November 1, 2012.

65. Italiano A, Ortholan C, Oudard S, et al. Docetaxel-based chemotherapy in elderly patients (age 75 and older) with castration-resistant prostate cancer. Eur Urol. 2009;55(6):1368-1375. 
66. Berthold DR, Pond GR, Soban F, de Wit R, Eisenberger M, Tannock IF. Docetaxel plus prednisone or mitoxantrone plus prednisone for advanced prostate cancer: updated survival in the TAX 327 study. J Clin Oncol. 2008;26(2):242-245.

67. Nekolla EA, Kellerer AM, Kuse-Isingschulte M, Eder E, Spiess H. Malignancies in patients treated with high doses of radium-224. Radiat Res. 1999;152(Suppl 6):S3-S7.

68. Kossman SE, Weiss MA. Acute myelogenous leukemia after exposure to strontium- 89 for the treatment of adenocarcinoma of the prostate. Cancer. 2000;88(3):620-624.

69. Saylor PJ, Lee RJ, Smith MR. Emerging therapies to prevent skeletal morbidity in men with prostate cancer. J Clin Oncol. 2011;29(27): 3705-3714

70. Bristol-Myers Squibb. Randomized Study Comparing Docetaxel Plus Dasatinib to Docetaxel Plus Placebo in Castration-Resistant Prostate Cancer (READY). In: ClinicalTrials.gov [website on the Internet]. Bethesda, MD: US National Library of Medicine; 2012 [updated October 5, 2012]. Available from: http:/clinicaltrials.gov/ct2/show/NCT00744497. NLM identifier: NCT00744497. Accessed November 1, 2012.

71. Hussain M, Smith MR, Sweeney C, et al. Cabozantinib (XL184) in metastatic castration-resistant prostate cancer (mCRPC): Results from a phase II randomized discontinuation trial. J Clin Oncol. 2011;29(Suppl):Abstr 4516

72. Exelixis. Study of Cabozantinib (XL184) Versus Prednisone in Men with Metastatic Castration-resistant Prostate Cancer Previously Treated with Docetaxel and Abiraterone or MDV3100 (COMET-1). In: ClinicalTrials. gov [website on the Internet]. Bethesda, MD: US National Library of Medicine; 2012 [updated October 2, 2012]. Available from: http://clinicaltrials.gov/ct2/show/NCT01605227. NLM identifier: NCT01605227. Accessed November 1, 2012.
73. Exelixis. Study of Cabozantinib (XL184) Versus Mitoxantrone Plus Prednisone in Men with Previously Treated Symptomatic Castrationresistant Prostate Cancer (COMET-2). In: ClinicalTrials.gov [website on the Internet]. Bethesda, MD: US National Library of Medicine; 2012 [updated October 11, 2012]. Available from: http://clinicaltrials.gov/ ct2/show/NCT01522443. NLM identifier: NCT01522443. Accessed November 1, 2012.

74. Algeta ASA. A Study of Alpharadin ${ }^{\circledR}$ with Docetaxel in Patients with Bone Metastasis From Castration-Resistant Prostate Cancer (CRPC). In: ClinicalTrials.gov [website on the Internet]. Bethesda, MD: US National Library of Medicine; 2012 [updated May 11, 2012]. Available from: http:/clinicaltrials.gov/ct2/show/NCT01106352. NLM identifier: NCT01106352. Accessed November 1, 2012.

75. DeWeese TL, Song DY. Current evidence for the role of combined androgen suppression and radiation in the treatment of adenocarcinoma of the prostate. Urology. 2000;55(2):169-174.

76. Quadramet ${ }^{\circledR}$ (samarium Sm 153 lexidronam injection) [prescribing information]. Langhorne, PA: EUSA Pharma (USA) Inc; 2009.

77. Metastron ${ }^{\mathrm{TM}}$ (strontium-89 chloride injection) [prescribing information]. Arlington Heights, IL: GE Healthcare; 2006.

\section{Publish your work in this journal}

Cancer Management and Research is an international, peer-reviewed open access journal focusing on cancer research and the optimal use of preventative and integrated treatment interventions to achieve improved outcomes, enhanced survival and quality of life for the cancer patient. The journal welcomes original research, clinical \& epidemiological

\section{Dovepress}

studies, reviews \& evaluations, guidelines, expert opinion \& commentary, case reports \& extended reports. The manuscript management system is completely online and includes a very quick and fair peerreview system, which is all easy to use. Visit http://www.dovepress.com/ testimonials.php to read real quotes from published authors. 